\title{
¿POR QUÉ ÚLTIMOS? LAS PEORES SITUACIONES DE CALIDAD DE VIDA EN LA ARGENTINA (2010)
}

Guillermo Angel Velázquez'

Fernando Ariel Manzano²

Resumen: A partir de inicios de la década de 1980, disponemos de información socioeconómica y ambiental acerca de la calidad de vida que nos permite una comprensión adicional de los procesos de cambio y permanencia en el territorio argentino. En este artículo, hemos puesto nuestro foco en los lugares que padecen peores situaciones de calidad de vida a partir de la nueva evaluación en 2010. Aunque los departamentos del Nordeste han logrado algunas mejoras en los últimos años, la región sigue siendo la que sufre peor situación relativa. Cinco de las diez unidades del país con peores condiciones socioeconómicas y ambientales (sobre un total de 525 departamentos) se localizan en esta región. En Ramón Lista (último lugar) la explotación petrolífera y los agronegocios impactaron en las condiciones de vida y generaron conflictos.

Palabras-clave: Argentina; Calidad de vida; Pobreza; Diferencias socioeconómicas; Diferencias ambientales.

1 Instituto de Geografía, Historia y Ciencias Sociales (CONICET/UNCPBA) - Argentina - gvelaz@fch. unicen.edu.ar

2 IGEHCS/CIG - Universidad Nacional del Centro de la Provincia de Buenos Aires (CONICET/ UNCPBA)

- Buenos Aires - Argentina - fernandoarielmanzano@fch.unicen.edu.ar 


\section{WHY LAST? WORST SITUATIONS OF QUALITY OF LIFE IN ARGEN- TINA (2010)}

Abstract: Since beginning of 1980s, we have socioeconomic and environmental information about the Quality of Life that allows us an additional understanding of the processes of change and permanence in Argentina's territory. In this article, we have put our focus on the places that show worst situations of Quality of Life obtained from the new evaluation in 2010. Although the Northeastern departments have made some improvements in recent years, the region continues in the worst relative situation. Five of this ten units with worst socioeconomic and environmental conditions are located in this region. They are 525 departments in total. In Ramón Lista (last place) oil exploitation and agribusiness impacted Quality of Live and generated conflicts.

Keywords: Argentina; Quality of Life; Poverty; Socioeconomic differences; Environmental differences.

\section{Introducción: La calidad de vida desde un punto de vista territorial}

La calidad de vida es una medida de logro respecto de un nivel establecido como "óptimo" teniendo en cuenta dimensiones socioeconómicas y ambientales dependientes de la escala de valores prevaleciente en la sociedad y que varían en función de las expectativas de progreso histórico.

Es decir que, mientras la pobreza se mide con respecto a un "mínimo" (necesidades básicas o línea de pobreza), la calidad de vida se mide con respecto a una situación "óptima" (máximo ideal que se podría lograr). Mientras el umbral de la pobreza es relativamente fijo, dado que apunta a la satisfacción de necesidades básicas, el óptimo de la calidad de vida es más variable (y ascendente), ya que la escala de valores y, sobre todo, las expectativas cambian.

La formulación de un índice de bienestar con cierta pretensión de generalización o universalidad no es aún una cuestión totalmente resuelta, pues depende de numerosos factores tales como: procesos históricos, escala de valores de la sociedad, expectativas, vivencias individuales y colectivas, dimensiones privadas (ingresos, nivel de instrucción) y públicas (accesibilidad, cuestiones ambientales), escala de análisis, ajuste con la información disponible o georeferenciación y validación de los resultados obtenidos.

Para comparar cuantitativamente la calidad de vida en cada uno de los departamentos (mínima unidad de división política territorial) hemos considerado las dimensiones socioeconómica (educación, salud y vivienda) y ambiental (recursos recreativos de base natural, recursos recreativos socialmente construidos y 
problemas ambientales). Estos, aspectos, ampliamente utilizados en los estudios sobre calidad de vida (Abba, 2010; Baxendale et al., 2012; Bolsi et al., 2009; Celemín, 2007; Formiga, 2003; Gómez, 2011; Garnica, 2005; Halperín, 1994; Lucero et al., 2007; Marinelli et al., 2005; Meichtry; Fantín, 2008; Mikkelsen et al.; 2013; Tonón et al., 2003; Torrado, 2007; Velázquez, 2001, 2008, 2016) serán aproximadas a partir de la selección de variables y, posteriormente, traducidas a números-índice para garantizar su comparabilidad y hacer posible un ordenamiento.

\section{Dimensión socioeconómica de la calidad de vida}

La educación, la salud y la vivienda son aspectos centrales de las políticas públicas que la sociedad argentina pone en el nivel más alto de su escala de valores y, por ende, son consideradas centrales para la diferenciación del bienestar de la población. Para su "medición" nos valdremos de las variables más significativas y discriminantes disponibles para todo el territorio. Como hay variables de costo y de beneficio todas fueron tratadas numéricamente para su manejo estadístico (puntajes omega). Esto permitió hacer comparables los siguientes indicadores de los 525 departamentos.

\section{1) Educación:}

- Porcentaje de población de 15 años o más que ya no asiste y con nivel de instrucción alcanzado menor a primario completo (cuadros 7.8 Censo 2001 y p 29 Censo 2010).

- Proporción de población de 15 años o más que ya no asiste y con nivel de instrucción alcanzado universitario completo (cuadros 7.8 Censo 2001 y p 29 Censo 2010).

\section{2) Salud:}

- Tasa de mortalidad infantil (TMI) según lugar de residencia de la madre. (Ministerio de Salud. Dirección de Estadísticas e información de salud-DEIS). Se toma la media de los tres años pericensales para disminuir las oscilaciones aleatorias propias de esta tasa. ${ }^{3}$

- Proporción de población sin cobertura por obra social, plan de salud privado o mutual (cuadros 6.3 Censo 2001 y P 12 Censo 2010).

3 También hicimos pruebas con los quinquenios pericensales (por ejemplo 1999-2002), pero el resultado terminaba ocultando algunas de las variaciones reales. (Vega et al., 2006) 


\section{3) Vivienda:}

- Porcentaje de población que reside en hogares que tienen inodoro sin descarga de agua o carecen de inodoro. (cuadros 4.6 Censo 20014 y P 40 Censo 2010).

- Proporción de población en hogares hacinados, considerando como tales a aquellos que superan las 2 personas por cuarto. (cuadros 4.8 Censo 2001 y $\mathrm{H} 9$ Censo 2010).

\section{Dimensión ambiental de la calidad de vida}

La Argentina posee gran diversidad de paisajes y situaciones ambientales que favorecen o disminuyen el bienestar; por eso resultó un desafío la estructuración de estas dimensiones y su normalización con puntajes omega. Para su validación se contrastaron y pusieron a prueba los resultados durante un período de más de cinco años (Velázquez y Celemín, 2013). En este caso también hay variables de costo (problemas ambientales) y otras de beneficio (recursos recreativos), que se detallan a continuación:

4) Recursos recreativos de base natural (RRBN)

- Playas, balnearios a orillas de ríos, lagos, lagunas o diques, centros termales, nieve/hielo (posibilidad de actividades recreativas invernales), relieve, espejos y cursos de agua, parques y espacios verdes.

(Fuente: Información Municipal/terreno/imágenes satelitales).

5) Recursos recreativos socialmente construidos (RRSC)

- Estética/Patrimonio urbano, centros culturales, centros comerciales y de esparcimiento, centros deportivos.

(Fuente: Información Municipal/terreno).

6) Problemas ambientales (PA):

- Uso de plaguicidas en agricultura. (Defensoría del Pueblo. Atlas Ambiental de la Niñez, 2009).

- Participación de Industria y minería en el PBG. (INDEC, 2003).

- Contaminación/ Ruido /Congestionamiento. (Información Municipal/terreno/escala urbana).

4 Aquí también hemos incluido los casos de retrete "ignorado", suponiendo que la mayoría de estos reflejan la carencia del artefacto en cuestión. 
- Localizaciones peligrosas. (Información Municipal/terreno/imágenes satelitales).

- Localizaciones con Externalidades negativas. (Información Municipal/terreno/imágenes satelitales).

- Inseguridad. Tasa de hechos delictivos por cada 10.000 habitantes. (Dirección Nacional de Política Criminal, 2008).

- Asentamientos precarios. \% de población residente en villas miseria. (Argentina. INDEC. Censo Nacional 2001, Información inédita, 2004).

- Basurales. \% de población residente a menos de 300 metros de un basural a cielo abierto. (Argentina. INDEC. Censo Nacional 2001, Información Inédita, 2004).

- Sismicidad y vulcanismo. (Chiozza et al, 1987).

- Tornados. (Geosistemas, 1997).

- Inundabilidad. (Argentina. INDEC. Censo Nacional 2001, Información inédita, 2004).

- Malestar climático. (IRAM, 1996).

Influencia de cada dimensión en el Índice de de Vida (ICV)

Cuadro 1 - Peso relativo de cada variable en el Índice de Calidad de Vida

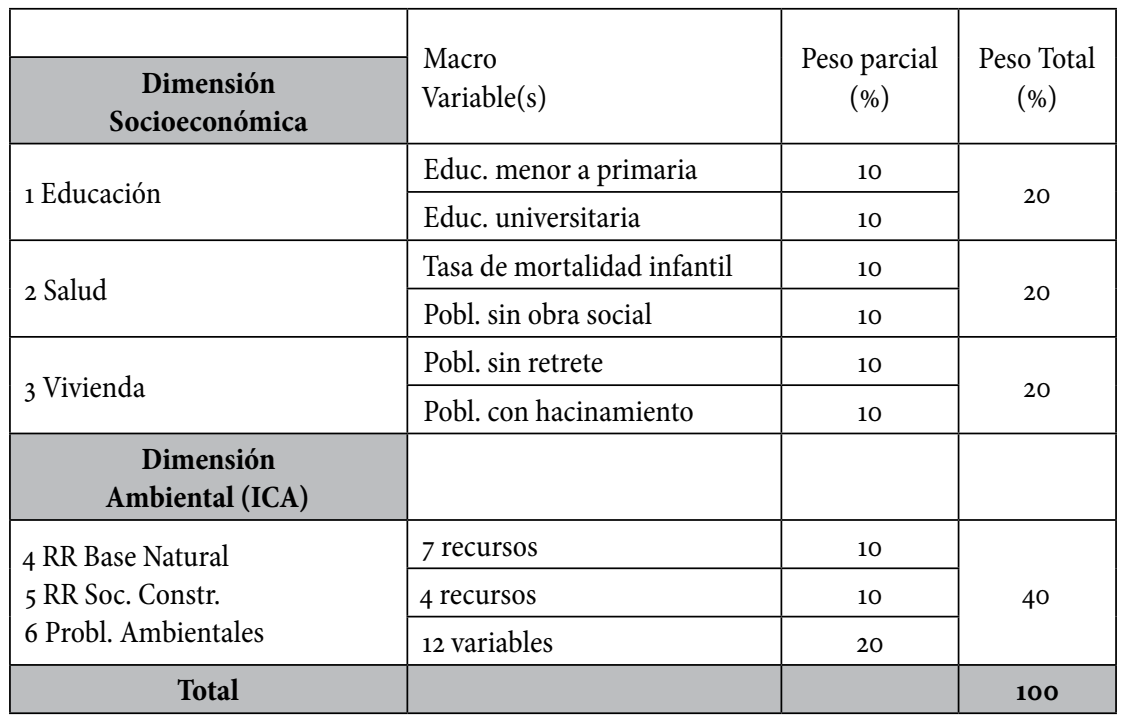

Fuente: Velázquez, 2016

Consideramos que este índice resulta, en general, representativo de la escala de valores de la población argentina, cuya gran mayoría (92\%) es urbana. Es probable, por tanto, que en los contextos que tienen mayor proporción de población rural y 
campesina sean relevantes otros aspectos de la calidad de vida que podrían ensayarse, aunque no extrapolarse a todo el territorio nacional. En este sentido son relevantes los aportes de Mikkelsen (2006) para la población rural de la región pampeana.

Al difundirse los "ranking" de calidad de vida en la Argentina fueron mucho mayores las implicancias políticas y mediáticas de hacer visible qué lugares ocupaban los últimos puestos antes que los primeros. Tanto políticos como periodistas y la gran mayoría de la población, que virtualmente ignoraban su existencia, se vieron obligados a tomarlos en consideración y a ejecutar políticas públicas para asistirlos. Esto nos animó, a pesar de las críticas que puedan hacérsele al índice, ${ }^{5}$ a convalidarlo como herramienta a la hora de mostrar las fragmentaciones y diferencias de oportunidades a lo largo del territorio nacional.

\section{Las peores situaciones y el contexto nacional}

Meichtry y Fantín (2016) sostienen que los estudios sobre evolución de la calidad de vida llevados adelante a partir de inicios de la década de 1990 (Velázquez, 2001; Velázquez, 2008; Velázquez y Celemín 2013, entre otros) han contribuido sustantivamente a delinear y comprender los procesos de cambio vividos en la sociedad y la economía de Argentina a través de un índice de evaluación sintética que busca poner en el centro del análisis la población y la sociedad en su conjunto, cuyos niveles de calidad de vida y bienestar se convierten, en consecuencia, en un barómetro de evaluación de resultados de las políticas de todo orden generadas por las autoridades responsables, para producir cambios a partir de las potencialidades y las carencias de los diferentes territorios, de sus historias y de sus procesos de evolución sociales, económicos, políticos y culturales.

..."a pesar de la existencia de diferentes condiciones ambientales con paisajes portadores de disímiles potenciales socioeconómicos, de la generación, en grandes rasgos, de tres historias notoriamente distintas de ocupación del espacio y de modos diferenciados de inserción en el mundo del capital y del mercado ${ }^{6}$, se han generado en los distintos subambientes del Nordeste, productos de territorialización que terminan convergiendo en instalar a la región en ambos extremos de la dicotomía calidad de vida-pobreza. Esto es, con los niveles más bajos en la escala nacional en el primer término de la ecuación y en los más elevados, en el segundo caso.

5 El índice intenta medir la calidad de vida de la población, pero no pretende dar cuenta de situaciones más estructurales, como ser los efectos de sectores de la actividad primaria sobre la distribución del ingreso, o la disputa por el espacio entre las poblaciones indígenas con sus forma de vida "pre-modernas" y el avance de sistemas de producción excluyente.

6 Se consideran los diferentes procesos del ambiente misionero, de la provincia de Corrientes, pionera en su ocupación territorial, y de las provincias insertas en la planicie chaqueña, ingresantes tardías en la organización nacional. 
En la obtención de tan magros resultados consideramos que los factores extraregionales ligados a la inserción de Argentina en el sistema mundial, junto con el accionar de los gobiernos y las clases dirigentes y empresarias locales y nacionales, no lograron o no supieron aprovechar y desarrollar las diferentes potencialidades del medio natural y de las propiedades del capital social. También debe aceptarse la idea de que las fuerzas del mercado no requirieran momentáneamente de las mismas dentro de ese largo continuum entre determinismo y posibilismo" (Meichtry y Fantin, 2008: 299).

Figura 1 - Calidad de vida en la Argentina (2010)

10 mejores y 10 peores situaciones

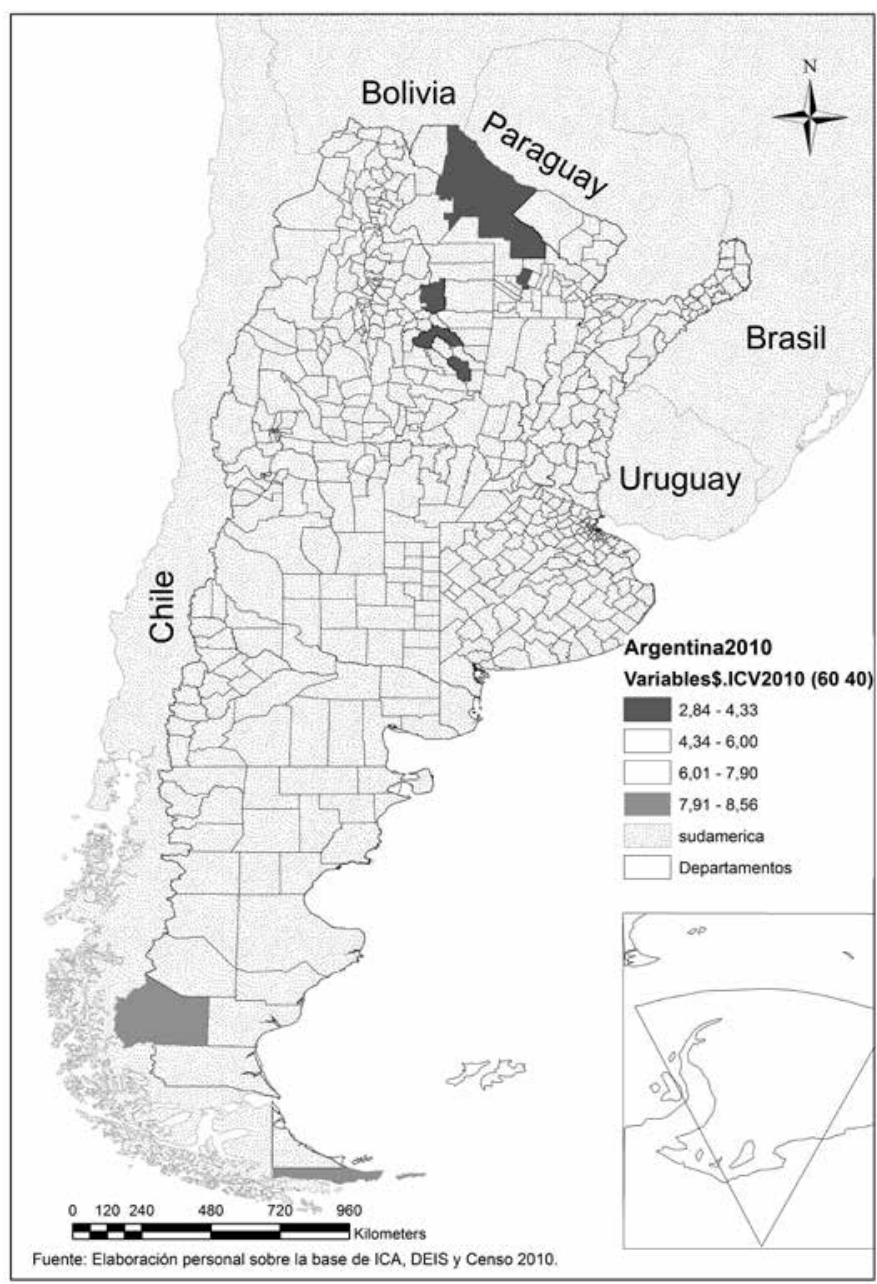

Fuente: Elaboración personal sobre la base de Velázquez, 2016 
Considerando la totalidad de los 525 departamentos/partidos/comunas de la Argentina, las 10 últimas unidades en el índice de calidad de vida corresponden a dos grandes áreas de pobreza:

a) El corazón aborigen del Chaco. Incluye tres departamentos del oeste de Formosa (cercanos a la triple frontera Argentina-Bolivia-Paraguay), uno del interior de Salta (Rivadavia), y uno de Chaco (General Güemes). ${ }^{7}$

b) El campesinado santiagueño. Abarca cuatro departamentos agroforestales.

Ambas áreas fueron caracterizadas por Bolsi y Paolasso (2009) como "Núcleos duros de la pobreza". Los autores identificaban, asimismo, cuatro áreas más: los Esteros y campesinos de Corrientes, el Chaco algodonero, La meseta indígena de Misiones y la Puna.

Figura 2 - Áreas con peores situaciones de calidad de vida (2010)

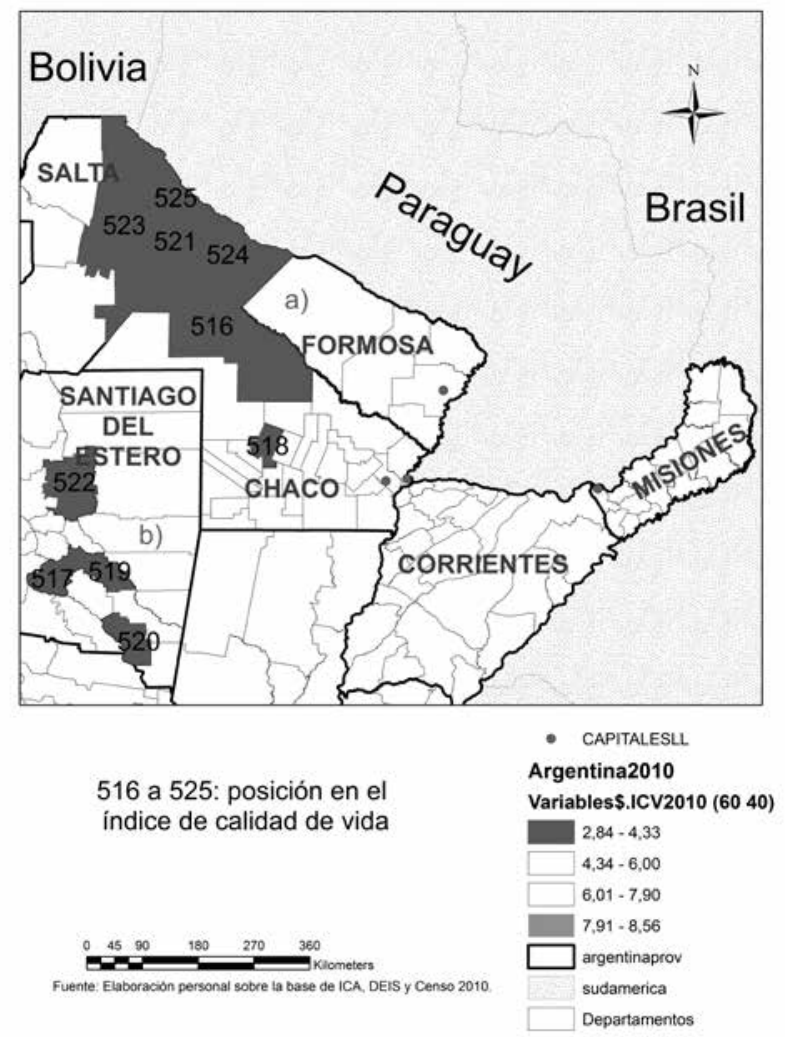

Fuente: Elaboración personal sobre la base de Velázquez, 2016

7 También aparece un departamento algodonero en el interior del Chaco, cercano a este grupo. 
Una caracterización general de este conjunto de departamentos muestra que se trata, en su mayoría, de unidades encabezadas por pueblos pequeños (menores a 2000 hab.), con predominio de población rural dispersa (es decir no agrupada en parajes o localidades). Otra característica son los bajos niveles de educación formal; alrededor del $40 \%$ de la población que ya no estudia no completó el nivel primario (oscila entre $47 \%$ y $31 \%$ ). A la vez hay muy baja proporción de graduados universitarios, no sólo por la ausencia de establecimientos educativos sino también por la estructura productiva de estas áreas.

A pesar de las mejoras en el sistema de salud durante los últimos años, siguen registrándose altas Tasas de Mortalidad Infantil (TMI), que alcanzan hasta 37 por mil. Otro indicador relevante, no sólo con respecto a la salud sino también a la calidad y nivel de inclusión en el ámbito laboral es la altísima proporción de población (entre 70 y $80 \%$ ) que carece de cobertura por obra social (aporte obligatorio de los empleadores y trabajadores a un plan de salud). Por otra parte, las pautas culturales de la población originaria continúan rechazando la medicina occidental.

La calidad de las viviendas es muy deficiente: la proporción de población en viviendas sin retrete es muy alta (hasta $43 \%$ ). La población originaria no acostumbraba construir baños en el interior de la vivienda, por lo que la carencia material se complementa muy fuertemente con razones culturales. También los factores ambientales (calor, sequía, aislamiento) influyen negativamente por la proliferación de plagas, virus y diversas enfermedades que se potencian con la falta de higiene (chagas, cólera, dengue). También hay problemas de hacinamiento (hasta $84 \%$ de la población reside en viviendas con más de dos personas por cuarto). Las viviendas precarias y pequeñas albergan a grupos de población relativamente numerosos en virtud de la persistencia de hogares multipersonales no familiares y de familias extendidas y compuestas en ámbitos con aún alta fecundidad relativa. Asimismo, el entorno y las pautas culturales posibilitan, desde edades tempranas, el transcurrir mucho tiempo al aire libre.

La vida cotidiana transcurre en un entorno con recursos recreativos de base natural relativamente escasos. Tenemos, en primer lugar, a los vinculados con la vegetación y la fauna silvestre -ambos sujetos a degradación desde hace décadas-; le siguen los escasos espejos y cursos de agua -la mayoría alóctonos y sujetos a los vaivenes de la estacionalidad climática-, por lo que su utilización como suministro para consumo relativiza su uso recreativo.

Los recursos recreativos socialmente construidos son particularmente deficitarios: el aislamiento, la escasa densidad de población, la ausencia de ciudades de cierta dimensión, la localización periférica respecto de los centros de 
decisión, agravada por la escasa magnitud del "mercado", todo ello, en un marco de necesidades más urgentes, relega las cuestiones recreativas a un segundo plano. Los gobiernos municipales organizan fiestas o actividades de esparcimiento buscando paliar estas necesidades.

Los problemas ambientales de este territorio se vinculan con la aridez, especialmente notoria en algunos ciclos y con el malestar climático (temperaturas extremadamente altas). La sistemática degradación del monte nativo, vinculada con el desmonte especulativo y agro-pastoril, contribuye a agravar este problema. Por otro lado, las actividades de subsistencia se ven perjudicadas por la sobre-pesca, la disminución de fauna para caza y la creciente escasez y degradación de frutos y vegetales del monte.

Arenas (2003: 140-142) señala que los Wichis y Matacos desconocían completamente los productos de almacén. Estos fueron introducidos por los criollos, que venían a buscarlos desde los ingenios de Salta y Jujuy y los cultivadores de algodón del Este. Así se abandonaron los productos de explotación tradicional, incluyendo árboles y plantas que no se aprovecharon más. En este sentido, los ancianos Tobas hacían notar que la "comida de los blancos", si bien sacia, produce en las personas una particular "flojera". Los principales productos que compran son: harina, grasa, azúcar, yerba, sémola, frangollo, sal, aceite, arroz, cebolla, carne y fideos.

Una mirada a los principales indicadores de calidad de vida de estos departamentos permite mostrar cómo se ubican en los últimos lugares de calidad de vida en la Argentina. Pero una mirada a la estructura económico-productiva ayuda a entender también el por qué:

Dentro de los intereses de la etapa del mercantilismo, el amplio "territorio indio del Norte" no despertó mayor interés. Así, la aproximación a la comarca del Gran Chaco fue casi excluyentemente periférica, forzada por la inexistencia de las riquezas requeridas, por un ambiente natural inhóspito y por una población aborigen de cazadores-recolectores y guerreros.

La ocupación definitiva de la planicie, se efectuó en forma centrípeta a partir del modelo periférico de acercamiento prevaleciente de la etapa colonial, avanzando hacia el corazón del territorio. Las causas obedecen fundamentalmente a las demandas extraregionales de maderas duras del bosque chaqueño requeridas primero para la instalación de puertos y ferrocarriles y luego para la producción de tanino. ${ }^{8}$

8 Cf. mapa esquemático de ocupación del espacio en Meichtry y Fantin (2001: 118). 
Se generaron tres anillos de ocupación, con diferentes estructuras fundiarias: las colonias perimetrales, los latifundios intermedios y el corazón fiscal (Bruniard, 1979).

Tenemos un marco en donde el modo de producción capitalista coexiste con economías de subsistencia (particularmente pescadores y cazadores). El escaso y mal pago empleo público se complementa con comercio modesto (por la reducida demanda). Las actividades que generan más riqueza (petróleo, soja) se han desarrollado con una lógica de "enclaves" que no "derraman" en la zona. El petróleo extraído es trasladado mediante oleoductos hacia refinerías externas que no generan empleos ni agregan valor, salvo ínfimos tributos, utilizados sin mayor control por parte de los gobiernos locales. La expansión de la soja, además de agravar los problemas ambientales por los desmontes y el uso de agresivos paquetes tecnológicos, se convierte en un mecanismo legal e ilegal de riquezas hacia agentes extra-regionales y además genera muy pocos empleos.

Por otra parte la elaboración de artesanías no alcanza una escala extra-regional. Hay total ausencia de establecimientos manufactureros $u$ otro tipo de elaboración de las materias primas locales. El capitalismo impactó, asimismo, en las pautas culturales, pero no de manera beneficiosa, sino perjudicial; por ejemplo, la creciente afición por las bebidas alcohólicas industrializadas, particularmente vino, ginebra y cerveza, que contribuye a degradar más aún la calidad de vida de los sectores más vulnerables.

Cuadro 2 - Diez últimas unidades en el "ranking” de calidad de vida (2010)

\begin{tabular}{|c|c|c|c|c|c|c|c|c|c|c|}
\hline \multirow[b]{2}{*}{ 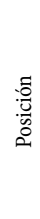 } & \multirow[b]{2}{*}{$\begin{array}{l}\text { Departamento } \\
\text { (Provincia) }\end{array}$} & \multirow[b]{2}{*}{$\begin{array}{c}\text { Principales } \\
\text { Localidades (hab) }\end{array}$} & \multirow[b]{2}{*}{ 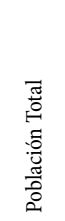 } & \multicolumn{2}{|c|}{ Educación } & \multicolumn{2}{|c|}{ Salud } & \multicolumn{2}{|c|}{ Vivienda } & \multirow[b]{2}{*}{ 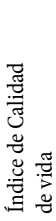 } \\
\hline & & & & 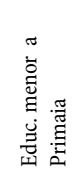 & 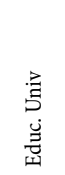 & 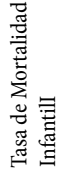 & 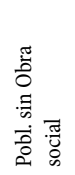 & 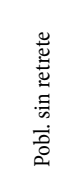 & 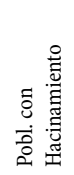 & \\
\hline 516 & $\begin{array}{c}\text { General Güemes } \\
\text { (Chaco) }\end{array}$ & $\begin{array}{l}\text { JJ Castelli } \\
(27.201 \text { hab. }) \\
\text { Miraflores } \\
\quad(4.737 \text { hab. })\end{array}$ & 67.132 & $40,02 \%$ & $1,79 \%$ & $\begin{array}{c}21,98 \\
\% 0\end{array}$ & $75,48 \%$ & $19,55 \%$ & $52,45 \%$ & 4,33 \\
\hline 517 & $\begin{array}{l}\text { Atamisqui } \\
\text { (Santiago del } \\
\text { Estero) }\end{array}$ & $\begin{array}{l}\text { Villa Atamisqui } \\
\quad(3.289 \text { hab.) }\end{array}$ & 10.923 & $42,60 \%$ & $0,42 \%$ & $\begin{array}{c}13,70 \\
\% 0\end{array}$ & $71,80 \%$ & $18,24 \%$ & $49,13 \%$ & 4,28 \\
\hline 518 & $\begin{array}{l}\text { Independencia } \\
\text { (Chaco) }\end{array}$ & $\begin{array}{l}\text { Campo Largo } \\
\text { (9.069 hab.), } \\
\text { Avia Terai } \\
(6.203 \text { hab.) }\end{array}$ & 22.411 & $40,04 \%$ & $0,80 \%$ & $\begin{array}{c}19,96 \\
\% 0\end{array}$ & $73,84 \%$ & $10,99 \%$ & $48,31 \%$ & 4,23 \\
\hline 519 & $\begin{array}{l}\text { Avellaneda } \\
\text { (Santiago del } \\
\text { Estero) }\end{array}$ & $\begin{array}{l}\text { Colonia Dora } \\
\quad(3.364 \text { hab.), } \\
\text { Icaño } \\
\quad(1.975 \text { hab. })\end{array}$ & 20.763 & $37,96 \%$ & $0,33 \%$ & $\begin{array}{c}16,10 \\
\% 0\end{array}$ & $73,99 \%$ & $15,24 \%$ & $55,06 \%$ & 4,20 \\
\hline
\end{tabular}




\begin{tabular}{|c|c|c|c|c|c|c|c|c|c|c|}
\hline 520 & $\begin{array}{c}\text { Mitre } \\
\text { (Santiago del } \\
\text { Estero) }\end{array}$ & $\begin{array}{l}\text { Villa Unión } \\
\text { (510 hab.) }\end{array}$ & 1.890 & $45,47 \%$ & $0,44 \%$ & $\begin{array}{c}13,33 \\
\% 0\end{array}$ & $74,97 \%$ & $14,02 \%$ & $40,48 \%$ & 4,19 \\
\hline 521 & $\begin{array}{l}\text { Matacos } \\
\text { (Formosa) }\end{array}$ & $\begin{array}{c}\text { Ingeniero Juarez } \\
\quad(12.798 \text { hab. })\end{array}$ & 14.375 & $31,04 \%$ & $1,93 \%$ & $\begin{array}{c}26,40 \\
\%\end{array}$ & $69,71 \%$ & $16,53 \%$ & $54,78 \%$ & 4,19 \\
\hline 522 & $\begin{array}{c}\text { Figueroa } \\
\text { (Santiago del } \\
\text { Estero) }\end{array}$ & $\begin{array}{l}\text { La Cañada } \\
\qquad(1.696 \text { hab.) }\end{array}$ & 17.820 & $42,81 \%$ & $0,21 \%$ & $\begin{array}{c}8,00 \\
\%\end{array}$ & $74,27 \%$ & $25,06 \%$ & $58,95 \%$ & 4,02 \\
\hline 523 & $\begin{array}{l}\text { Rivadavia } \\
\text { (Salta) }\end{array}$ & $\begin{array}{l}\text { Coronel. Solá } \\
\quad(4.714 \text { hab.) } \\
\text { La Unión } \\
\quad(2.353 \text { hab.) }\end{array}$ & 30.357 & $42,62 \%$ & $0,81 \%$ & $\begin{array}{c}16,87 \\
\%\end{array}$ & $78,74 \%$ & $31,24 \%$ & $68,74 \%$ & 3,18 \\
\hline 524 & $\begin{array}{l}\text { Bermejo } \\
\text { (Formosa) }\end{array}$ & $\begin{array}{l}\text { Laguna Yema } \\
\quad(3.617 \text { hab. })\end{array}$ & 14.046 & $46,33 \%$ & $0,89 \%$ & $\begin{array}{c}36,91 \\
\% 0\end{array}$ & $76,98 \%$ & $27,64 \%$ & $66,51 \%$ & 2,95 \\
\hline 525 & $\begin{array}{l}\text { Ramón Lista } \\
\text { (Formosa) }\end{array}$ & $\begin{array}{l}\text { El Potrillo } \\
\quad \text { (3.371 hab.) } \\
\text { General Mosconi } \\
\quad \text { (1.902 hab.) } \\
\text { El Quebracho } \\
\quad(415 \text { hab.) }\end{array}$ & 13.754 & $45,42 \%$ & $1,28 \%$ & $\begin{array}{c}20,08 \\
\% 0\end{array}$ & $76,52 \%$ & $42,87 \%$ & $84,33 \%$ & 2,84 \\
\hline
\end{tabular}

Fuente: Velázquez, 2016

\section{El último de la lista: Ramón Lista (Formosa)}

Dentro de este particular "ranking" queremos destacar la situación de la última unidad: el departamento Ramón Lista, situado en el extremo nor-occidental de Formosa, cercano a la triple frontera (Argentina, Bolivia, Paraguay).

El departamento se sitúa en una región casi desértica, a la que en una expedición militar llegaron soldados, que encontraron hacia 1900 un chorro o vertiente de agua que surgía del fondo de una cañón, por lo que tomaron al lugar como punto de descanso y referencia, denominándolo "Los Campos de la Cañada del Chorro de Agua", sintetizándola con el tiempo, simplemente como "El Chorro" (actualmente, General Mosconi), donde abrevaban miles de animales vacunos y cabríos en la época de esplendor de la zona. El agua surgía de la llamada "Cañada Madre".

Se trata de una llanura con escasa pendiente, que declina de noroeste a sudeste desde la cota 205 en Mosconi, hasta la ciudad de Formosa, situada a 65 m.

Hasta hace pocos años no contaba, siquiera con electricidad. Recientemente fue conectada a la red de electricidad provincial. Se brindaban servicios educativos elementales a través de "anexos" escolares. Los niños que asisten a las escuelas del departamento Ramón Lista de Formosa, son en su mayoría, pertenecientes a la etnia aborigen Wichi. Viven en condiciones de extrema pobreza, sin agua ni energía eléctrica, en viviendas precarias y hacinadas, con graves problemas de salud, desnutrición y avitaminosis. Su comunidad no tiene una economía planificada y su sustento depende en gran medida de la caza y de la pesca, como hace siglos. Carecen de infraestructura y servicios elementales y 
no son aún propietarios de las tierras en las que residen ancestralmente. Esta situación se agrava a partir de la irrupción de agronegocios sojeros y actividad petrolera que, a modo de enclaves, avasallaron y degradaron, ya sea por deforestación como por contaminación, territorios en donde se localizaban actividades tradicionales.

Cuadro 3 - Indicadores socioeconómicos de Ramón Lista (1980-2010)

\begin{tabular}{|c|c|c|c|c|c|c|c|c|c|}
\hline \multirow[b]{2}{*}{ Año } & \multirow[b]{2}{*}{$\begin{array}{l}\text { Posición } \\
\text { (en relación } \\
\text { al total) }\end{array}$} & \multirow[b]{2}{*}{$\begin{array}{c}\text { Población } \\
\text { Total } \\
\text { (habitantes) }\end{array}$} & \multicolumn{2}{|c|}{ Educación } & \multicolumn{2}{|c|}{ Salud } & \multicolumn{2}{|c|}{ Vivienda } & \multirow[b]{2}{*}{ 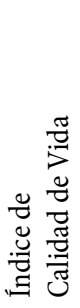 } \\
\hline & & & 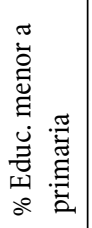 & 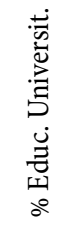 & 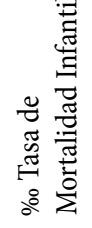 & 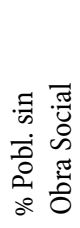 & 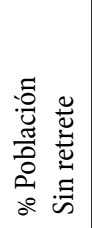 & 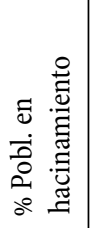 & \\
\hline 2010 & 525 de 525 & 13.754 & 45,42 & 1,28 & 20,08 & 76,52 & 42,87 & 84,33 & 2,84 \\
\hline 2001 & 511 de 511 & 10.781 & 67,11 & 0,49 & 21,26 & 86,79 & 96,7 & 85,42 & 2,74 \\
\hline 1991 & 497 de $501^{9}$ & 6.651 & 58,01 & 0,77 & 30,9 & 84,60 & 95,79 & 83,84 & 2,71 \\
\hline 1980 & $492 \mathrm{de} 497^{10}$ & 2.740 & 78,17 & $1,49 \mathrm{i}$ & 38,57 ii & & $96,94^{*}$ & @ & 2,49 \\
\hline
\end{tabular}

Fuente: Velázquez, 2016, Velázquez, 2008 y Velázquez, 2001.

Referencias:

i Corresponde a Universitario y Terciario completo ii TMI provincial ${ }^{*}$ Corresponde a viviendas deficientes (Inquilinatos, precarias, Rancho, otros) @ En 1980 se relevaban "personas por vivienda” y no por cuarto; en Ramón Lista había 4,78 (mucho hacinamiento en términos relativos).

Si bien el índice de calidad de vida de Ramón Lista tuvo modestas mejoras entre 1980 y 2010, estas no fueron suficientes como para quitarlo de los últimos puestos. El departamento se encuentra último desde el 2001, pero desde 1980 estuvo entre los cinco peores, evidenciando el carácter estructural de sus carencias: es la periferia de la región más postergada de la Argentina.

El 45,42\% de su población no pudo finalizar la escolaridad primaria. Esto lo ubica entre las peores situaciones del país (520/525). Durante los últimos años se han construido numerosos establecimientos educativos (antes predominaban los "anexos") y se incrementó sensiblemente la planta docente. Esto

9 Los últimos puestos en 1991 los ocupaban los deptos. de Chical Co, Curacó (La Pampa) y Rinconada (Jujuy).

10 Los últimos puestos en 1980 los ocupaban los deptos. de La Poma (Salta), Susques, (Jujuy), Santa Victoria (Salta), Santa Catalina (Jujuy) y Rivadavia (Salta). 
mejoró la situación respecto de los ochenta (cuando casi 80\% no había completado el primario).

Sólo 1,28\% de la población terminó la universidad (467/525). Esto implica una mejora frente al o,49\% del 2001. Esto está vinculado con dos procesos: por un lado la incorporación de técnicos universitarios asociados con la extracción petrolífera y, por otro, la radicación de personal universitario de salud que se incrementó durante los últimos años. A esto debe sumarse la acción de algunos organismos técnicos del Estado y de ONGs.

La Tasa de Mortalidad Infantil de 20,08 por mil es relativamente alta, pero no la peor del país (496/525). Hay, en este sentido, progresos vinculados con la acción del Estado, (centros de salud, atención materno-infantil, implemento de la asignación universal por hijo a escala nacional) fundamentalmente a partir de los primeros años del siglo XXI, para intentar mitigar la crítica situación, aunque tampoco debemos descartar un posible subregistro en algunas de las zonas más aisladas. Los resultados podrían mejorar si se venciera la ya mencionada desconfianza hacia la medicina occidental por parte de los pobladores originarios.

Figura 3 - Imágenes de Ramón Lista
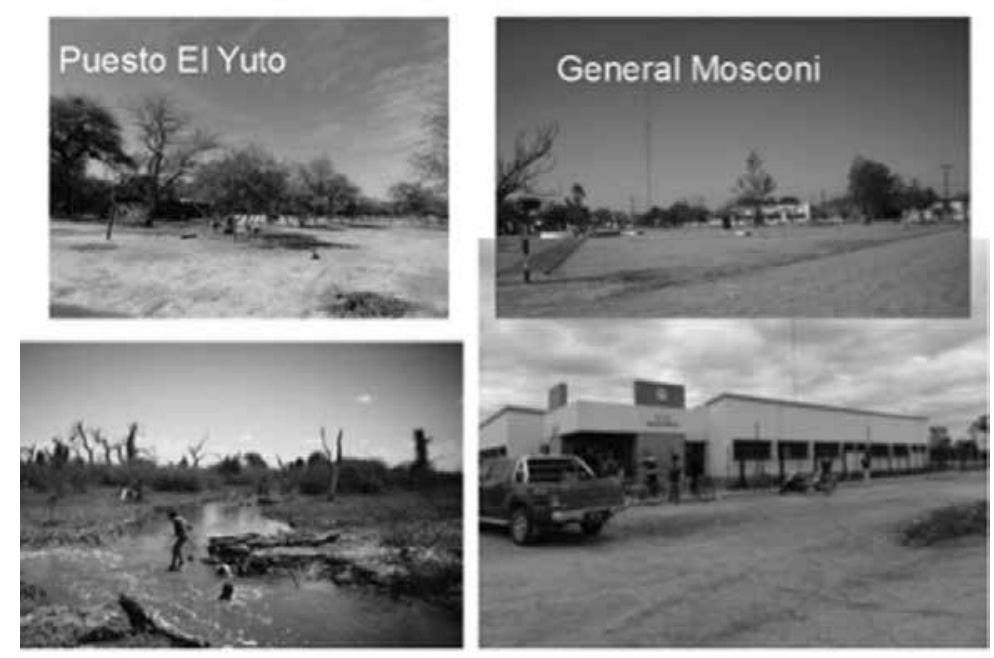

El predominio de actividades de subsistencia, el escaso empleo formal y los magros ingresos hacen que la enorme mayoría de la población $(76,52 \%)$ carezca de cobertura de salud por obra social. Los datos del 2010 lo ubican casi último (523/525). 
Las condiciones de vivienda de los pobladores de Ramón Lista resultan críticas, particularmente el hacinamiento, que reviste características estructurales de extrema gravedad, alcanzando al 84,33\% de la población en 2010 y lo coloca holgadamente en último lugar (525/525). Estas cifras no han mejorado en lo absoluto desde que se tiene registro estadístico (1991). El por qué puede explicarse por un marco de escasos ingresos, en un contexto de alta fecundidad, con estructura demográfica joven y escasísima intervención del Estado, tanto es salud reproductiva como en provisión de viviendas sociales. Para mostrar la gravedad de esta cuestión basta señalar que el departamento anteúltimo (Rivadavia en Salta) tiene casi 16 puntos menos de población que padece este problema. No hay excusas: la vivienda (construcción, ampliación, refacción) es un factor clave que puede ser fácilmente mejorado en esta zona, fundamentalmente si se tiene en cuenta que la gestión local cuenta con recursos provenientes de las regalías petroleras y de la explotación sojera que, como actividades concentradas en manos del capital financiero internacional, no "derraman" sobre la enorme mayoría de la población.

Otra forma de ver el problema es a partir de la población que carece de retrete. En este caso la situación también es pésima, ya que afecta al 42,87\% de la población (puesto 525/525). Una vez más, para mostrar la extrema gravedad del problema, basta señalar que el anteúltimo departamento se aleja 12 puntos de los dramáticos valores de Ramón Lista.

Las deficiencias habitacionales tienen gran responsabilidad en esta penosa situación y, paradójicamente serían la más fáciles de revertir, aún considerando las limitaciones culturales y materiales ya explicadas para la región. Desde luego sería indispensable una mayor intervención del estado en estos temas.

Continuaremos explicando las principales características estructurales de la población del departamento: la mayoría de la población reside el la zona rural y sólo El Potrillo supera el umbral de 2.000 habitantes.

Cuadro 4 - Población de Ramón Lista por localización y sexo (2010)

\begin{tabular}{|l|c|c|c|}
\hline \multirow{2}{*}{ Localidad } & \multicolumn{2}{|c|}{ Género } & \multirow{2}{*}{ Total } \\
\cline { 1 - 2 } & Varón & Mujer & \\
\hline Zona Rural & 4.225 & 3.841 & 8.066 \\
\hline El Potrillo & 1.652 & 1.719 & 3.371 \\
\hline General Mosconi (El Chorro) & 928 & 974 & 1.902 \\
\hline El Quebracho & 212 & 203 & 415 \\
\hline Total & 7.017 & 6.737 & 13.754 \\
\hline
\end{tabular}

Fuente: Argentina. INDEC, 2013. 
En todo el departamento no existe red cloacal, normalmente se utilizan las letrinas como sistema de evacuación. Tampoco existe gas por red; se utiliza gas en garrafas de $10 \mathrm{Kg}$. que suministran los comercios locales a altos precios. En las tres localidades mencionadas, desde hace pocos años, se dispone de energía eléctrica las 24 horas del día, que es obtenida en "Palmar Largo" mediante tres generadores de funcionamiento a gas.

El Potrillo es la principal localidad. Se sitúa muy cerca del yacimiento petrolífero de Palmar Largo (que, a modo de enclave, posee su propia pista de aterrizaje). Su crecimiento fue caótico, no existen calles asfaltadas, sólo escuela primaria y jardín de infantes, ambos inaugurados durante los noventa. La evolución del pueblo está ligada a la de las "migajas" que derrama el yacimiento y presenta las situaciones más adversas de calidad de vida de todo el departamento. Los intentos por intentar rescatar actividades tradicionales como la pesca a partir de emprendimientos menores (por ejemplo construcción de represas piscícolas), parecen no haber dado los resultados esperados. La localidad carece, casi por completo, de recursos recreativos.

General Mosconi (El Chorro), es la localidad más antigua, cabecera del partido y posee mayor infraestructura. Está situada en una cañada, tiene plaza, "paseo costanero", registro civil, barrios construidos (en general con viviendas pequeñas para el tamaño medio de los hogares), sucursal bancaria (con cajero automático), edificio municipal (muy modesto), nueva escuela, radio local (fm 101.7 del pueblo), comisaría, un modesto hospital, estación de servicio, talleres (soldaduras, reparaciones) y una sede social de la comunidad Wichi. En este caso, se instaló un matadero para intentar diversificar la economía y la calidad alimentaria. Para mitigar el calor, la localidad cuenta con una laguna cercana, que constituye su principal recurso recreativo.

Finalmente, El Quebracho posee sólo escuela primaria desde la década del setenta, dispone de antena de radio, y se sitúa cercana a una quebrada (curso de agua). La localidad es muy dispersa y prácticamente no se distingue en las imágenes satelitales.

Recordemos que la enorme mayoría de la población de Ramón Lista (8 mil de sus 14 mil hab.) vive fuera de las tres localidades mencionadas. Esto acentúa aún más sus padecimientos.

La estructura económica y social de Ramón Lista está escasamente diversificada. Lo que predomina abrumadoramente son las actividades de subsistencia (recolección, pesca, caza, artesanías), que están permanentemente amenazadas por la degradación ambiental y la sobreexplotación. Así, por ejemplo, una especie como el Chaguar, habitualmente disponible para ser utilizada para 
artesanías, escasea a tal punto que las mujeres tienen que recorrer hasta $50 \mathrm{~km}$ para obtenerlos.

Para los pocos trabajadores formales los niveles salariales son paupérrimos. Así, un trabajador municipal ganaba en febrero del 2013 entre 1200/1400\$ mensuales (aproximadamente u\$s 240). Esto representa una fuerte contradicción con los U\$S 250.000 diarios de petróleo que salen por día desde Ramón Lista hacia las destilerías de Campo Durán (Salta).

Podemos señalar que la explotación de petróleo en el oeste formoseño se inició en los ochenta, de la mano de la empresa estatal Yacimientos Petrolíferos Fiscales (YPF). Durante los noventa se sumaron otras firmas como Pluspetrol, CGC y Gran Tierra. Esta explotación es, sin embargo, marginal y tiene, históricamente, rendimientos decrecientes; no obstante, durante los últimos años se descubrieron nuevos yacimientos en Palmar Largo y se incrementaron las regalías petroleras. Tristemente estas actividades extractivas también incrementaron los problemas: las comunidades están siendo intoxicadas, los niños se están enfermando y la mayoría de la población vive en condiciones deplorables. A pesar de los intentos de ocultamiento, la compañía Pluspetrol ha tenido varias denuncias por contaminación del aire y del agua.

La expansión agrícola trae como consecuencia desmontes y venta de tierras. Asimismo entre los pobladores existen interrogantes respecto de las versiones de proyectos de localización de plantas nucleares.

La irrupción de la actividad sojera en este departamento se explica en el marco del proceso de "pampeanización" del Nordeste Argentino, que ha extendido cada vez más hacia el norte el límite de cultivos tradicionalmente pampeanos y sus consecuencias son tanto o más graves que las vinculadas con la explotación petrolífera.

Otra fuente de recursos está vinculada con la expansión de la telefonía celular, por la que Ramón Lista percibe derechos por la instalación de antenas de Telecom en el predio de la municipalidad.

En general la mayoría de la población tiene tradición comunitaria y asambleísta. A pesar de ello no logran obtener información respecto de la magnitud del petróleo extraído o de cuantas regalías se reciben por la explotación sojera. En general reina el oscurantismo y la provincia maneja estos temas directamente con los intendentes.

Las contradicciones y las necesidades son grandes. En general, en vez de atender los reclamos, desde el gobierno provincial se envían fuerzas de seguridad, en clara muestra de violencia institucional. A veces se suma también el gobierno nacional, con operativos de gendarmería y helicópteros. 
La protesta popular adoptó, últimamente, otras modalidades: A comienzos del 2013 las comunidades Wichis, además de cortar rutas (acceso a plantas petroleras en Palmar Largo durante más de dos meses), llegaron a tomar la propia Municipalidad. Los reclamos se refieren a: agua, luz, salud, justicia y tierras; dimensiones centrales de la calidad de vida, que relegan a Ramón Lista a la peor situación del país.

Son cientos las personas muertas en los últimos años por causas evitables relacionadas con la falta de atención de la salud. Durante 2013 se contabilizaron más de 30 muertes que la comunidad considera que pudieron haberse evitado. También reclamaron justicia por muertes y mutilaciones sufridas a partir de la represión de las protestas, que quedaron impunes.

La diarrea y la tuberculosis constituyen graves problemas de salud en esta área. La ruralidad de la población y las resistencias culturales dificultan la atención médica. Así, por ejemplo, para hacerse tratamientos con rayos (para tratamientos oncológicos) los pacientes tienen que desplazarse más de $500 \mathrm{~km}$. hasta Resistencia.

Avelino Tejada, (cacique de la comunidad wichí Cacique Colorado) sostiene que:

Esta es una zona petrolera y hay muchas bocas de pozo, mientras nosotros estamos sin vivienda, no tenemos centro de salud, no tenemos ambulancias, nos falta electricidad en muchas comunidades. En las escuelas mal construidas nuestros hijos no pueden estudiar en verano por el calor ni en invierno por el frío. Queremos que el gobierno nacional vea, tienen que venir. Nos sacan la tierra, alambran territorio sin consultarnos. Formosa tiene cincuenta años, pero nosotros habitamos aquí primero, no pueden sacarnos las tierras. Aquí vienen empresas muy grandes y ni siquiera estamos teniendo la posibilidad de ser empleados por ellos. No hay aborígenes en los yacimientos.

Por otra parte, otras áreas del Estado están trabajando intensamente en la zona. Así, desde el Instituto Nacional de Asuntos Indígenas se han efectuado trabajos de relevamiento de las tierras pertenecientes a más de una veintena de comunidades aborígenes del departamento Ramón Lista, tarea enmarcada en el cumplimiento de la Ley Nacional 26160 referida al Programa de Relevamiento Territorial de Comunidades Indígenas. Esto posibilita la titularización de tierras en las comunidades. Se trata de georeferenciar las tierras ocupadas tradicionalmente, actualmente y públicamente por las comunidades aborigenes.

El trabajo incluye, asimismo, información a través de un cuestionario socio-comunitario indígena, del segmento productivo, un informe antropológico como el de las migraciones internas y la historia misma de la comunidad, 
además de un informe agro-ecológico para conocer las potencialidades de la tierra, inclusive se agregaron las obras ejecutadas como escuelas, viviendas, centros de salud, hospitales, energía eléctrica y agua potable.

\section{Conclusiones}

Es importante señalar que la pretensión de generar un índice de calidad de vida de carácter universal, iría en detrimento de la posibilidad de captar las heterogéneas situaciones que se dan en un territorio, generadas por muchos factores interrelacionados tales como: procesos históricos, escala de valores de la sociedad, expectativas, vivencias individuales y colectivas, dimensiones privadas (ingresos, nivel de instrucción) y públicas (accesibilidad, cuestiones ambientales) etc.

El seguimiento de la evolución de la calidad de vida que llevamos adelante a partir de inicios de la década de 1980, nos permite una comprensión adicional de los procesos de cambios sociales y económicos de Argentina, y disponer de un instrumento de referencia a través del cual es posible cuantificar en términos relativos los resultados y efectos de las políticas aplicadas sobre el bienestar social.

Si bien en la nueva evaluación los niveles de calidad de vida en 2010 presentan mejorías, hemos corroborado que la región del Nordeste (en particular ciertos territorios), continúa siendo la región más desposeída de nuestro país. En esta región se encuentran cinco de los diez peores departamentos del país (tres pertenecen a Formosa y dos a Chaco). De los restantes departamentos cuatro pertenecen a la provincia de Santiago del Estero y uno a Salta.

Los diez departamentos de la Argentina que padecen peores situaciones de calidad de vida tienen características comunes: escaso peso demográfico, predominio de población rural dispersa, gran peso relativo de población aborigen y de actividades de subsistencia, fuertes carencias en servicios e infraestructura, estructuras económicas poco diversificadas, mecanismos de control y represión social, problemas de regularización dominial, conflictos sociales y ambientales, etcétera.

Estas características se reflejan en paupérrimas condiciones de educación, salud, vivienda, recursos recreativos y problemas ambientales.

Si bien la gran mayoría de estas unidades territoriales han mejorado (con respecto a sí mismas) en algunas dimensiones (muy especialmente en lo que respecta a salud y educación, particularmente durante el último período intercensal), los progresos no han sido de una magnitud tal que les permita salir del "final de la tabla". Por el contrario, casi todas ellas permanecen en esta triste posición relativa, con pocos cambios desde los ochenta. 
Estos resultados nos permiten afirmar que todos sus residentes tienen la posibilidad (y el derecho) de ser promovidos de esta situación. La dimensión de intervención más fácil es la vivienda y es, contradictoriamente, la que se muestra más relegada.

\section{Referências}

ABBA, Alberto. Revelaciones de los datos provisionales del Censo 2010. ¿Una nueva realidad de la Buenos Aires Metropolitana? Buenos Aires, FADU UBA, 2011.

ARENAS, Pastor. Etnografía y alimentación entre los Toba-Ñachilamole \#ek y WichíLluku'tas del Chaco Central: Argentina. Buenos Aires, el autor, 2003.

ARGENTINA. Defensoría del Pueblo de la Nación. Atlas del riesgo ambiental de la niñez de la Argentina. PNUD-UNICEF-OPS-OIT, 2009. Disponible en: <http://defensoresymedios.org.ar/wp-content/uploads/2010/04/Atlas.pdf $>$. Aceso em: 13 out. 2017.

ARGENTINA. Dirección nacional de política criminal. Estadísticas en materia de criminalidad. Ministerio de Justicia, Seguridad y Derechos Humanos, 2008. <http:// www.jus.gov.ar/areas-tematicas/estadisticas-en-materia-de-criminalidad.aspx $>$. Aceso em: 13 out. 2017.

ARGENTINA. INDEC. Censo Nacional de Población Hogares y Vivienda, 2001. 2001. Disponible en: $<$ http://www.indec.mecon.ar $>$. Aceso em: 13 out. 2017.

ARGENTINA. INDEC. PBG por provincia y sector de actividad económica, 2003.

Disponible en: <http://www.mecon.gov.ar/secpro/dir_cn/documentos/producto_ bruto_geografico.xls $>$. Aceso em: 13 out. 2017.

ARGENTINA. INDEC. Censo nacional de población, hogares y vivienda 2001. Buenos Aires. Trabajo especial de procesamiento de variables de hábitat 22.144/04, 2004.

ARGENTINA. INDEC. Censo Nacional de Población Hogares y Vivienda, 2010, 2010.

Datos disponibles en http://www.indec.mecon.ar>. Aceso em: 13 out. 2017.

ARGENTINA. INDEC. Censo Nacional 2010 de población, hogares y viviendas. Resultados definitivos, por provincias, departamentos y localidades. Base de datos REDATAM. Buenos Aires, 2013.

ARGENTINA. IRAM. Clasificación bioambiental de la República Argentina. Buenos Aires: Instituto Argentino de Normalización, 1996, pp. 26.

BAXENDALE, Claudia; BUZAI, Gustavo; MORINA, Jorge. Análisis socioespacial de la calidad de vida en el Gran Buenos Aires (Argentina) a inicios del siglo XXI. En B. Varela \& J. Vinuesa Angulo (Comp) Metrópolis. Dinámicas urbanas. Luján, UNLU, 2012.

BOLSI, Alfredo; PAOLASSO, Pablo. Geografía de la pobreza en el Norte Grande Argentino. Tucumán, el autor, 2009. 
BRUNIARD, Enrique. El Gran Chaco argentino. (Ensayo de interpretación geográfica). Geográfica 4. Resistencia, 1979.

CHIOZZA, Elena; FIGUEIRA, Ricardo e IGLESIAS, Alicia. Atlas total de la Repúbica Argentina. Buenos Aires: Centro Editor de América Latina, 1987.

CELEMÍN, Juan. El estudio de la calidad de vida ambiental: definiciones conceptuales, elaboración de índices y su aplicación en la ciudad de Mar del Plata, Argentina. Hologramática 7. Buenos Aires, 2007.

FORMIGA, Nidia. Una aproximación a la diferenciación socio-espacial y la calidad de vida intraurbana. En VI Jornadas Argentinas de Estudios de Población. Buenos Aires, AEPA-INDEC, 2003.

GARNICA, Viviana Hogares y características del hábitat donde se localizan: Un panorama nacional de la cobertura de servicios según el censo 2001. En G. Velázquez \& S. Gómez Lende, Desigualdad y calidad de vida en la Argentina (1991-2001). Tandil, Centro de Investigaciones Geográficas, 2005.

GEOSISTEMAS. Mapa de riesgos naturales en la Argentina. Buenos Aires. Geosistemas, 1997. GÓMEZ, Néstor J. La geografía y el abordaje de la fragmentación urbana latinoamericana. Saarbrücken, Editorial Académica Española, 2001.

HALPERÍN, Leopoldo. Condiciones de vida de la población de Mar del Plata 1992/1994. Mar del Plata: Facultad de Humanidades, UNMP. 1994.

LUCERO, Patricia; MIKKELSEN, Claudia; SABUDA, Fernando; ARES, Sofía; AVENI, Silvia y ONDARTZ, Alejandro. Calidad de vida y espacio: Una mirada geográfica desde el territorio local. Hologramática, 7. Buenos Aires, 2007.

MARINELLI, Claudia; CEPEDA, Rosana y GOMEZ LENDE, Sebastián. Geografía y técnicas estadísticas. Una aproximación metodológica al análisis temporal de la Calidad de vida en la Argentina. II Seminario Internacional sobre Población y Sociedad. Salta, GREDES-UNSA.

MEICHTRY, Norma y FANTIN, Alejandra. Las condiciones ambientales, procesos de ocupación y desarrollo y calidad de vida en el Nordeste de Argentina. En G. VELÁZQUEZ. Geografía, calidad de vida y fragmentación en la Argentina de los noventa. Análisis regional y departamental utilizando SIG's. Tandil, Centro de Investigaciones Geográficas, 2001.

MEICHTRY, Norma; FANTIN, Alejandra. Territorios en regresión. Calidad de vida y pobreza en el Nordeste argentino. En G. VELÁZQUEZ. Geografía y bienestar. Situación local, regional y global de la Argentina luego del censo de 2001. Buenos Aires, EUDEBA, 2008, pp. 299-321.

MEICHTRY, Norma; FANTIN, Alejandra. El Nordeste Argentino. En G. VELÁZQUEZ. Geografía y calidad de vida en Argentina. Análisis regional y departamental (2010). Tandil, IGEHCS, 2016. 
MIKKELSEN, Claudia. Ampliando el estudio de la calidad de vida hacia el espacio rural.

El caso del partido de General Pueyrredon, Argentina, Hologramática, vol. 2, núm. 5, 17-34, 2006.

MIKKELSEN, Claudia; ARES, Sofía, SABUDA, Fernando y LUCERO; Patricia. Calidad de vida urbana en la Argentina de la postconvertibilidad. XII Jornadas Argentinas de Estudios de Población. Bahía Blanca, UNS, 2013.

TONÓN, Graciela; AGUIRRE, Victoria y Rodríguez de la Vega, Lía. La calidad de vida en la Argentina. VII Jornadas de la Asociación de Estudios de Población de la Argentina. Tafí del Valle, UNT, 2003.

TORRADO, Susana. Población y bienestar. Buenos Aires, EDHASA, 2007

VEGA, Andrea; TORCIDA, Sebastián; VELÁZQUEZ, Guillermo. Análisis de la Evolución de la Tasa de Mortalidad Infantil en los departamentos de Argentina 1994-2003. En Salud Colectiva. Lanús, Universidad Nacional de Lanús, v. 2, n.3, dic. 2006, p. 237-247.

VELÁZQUEZ, Guillermo. Geografía, calidad de vida y fragmentación en la Argentina de los noventa. Análisis regional y departamental utilizando SIG. Tandil, CIG, UNICEN, 2001.

VELÁZQUEZ, Guillermo. Geografía y bienestar. Situación local, regional y global de la Argentina luego del censo de 2001. Buenos Aires, EUDEBA, 2008.

VELÁZQUEZ, Guillermo. Geografía y calidad de vida en Argentina. Análisis regional y departamental (2010). Tandil, IGEHCS, 2010.

VELÁZQUEZ, Guillermo; CELEMÍN, Juan Pablo. La calidad ambiental en la Argentina. Análisis regional y departamental (c. 2010). Tandil, CIG, 2013.

VELÁZQUEZ, Guillermo (Dir.) Geografía y calidad de vida en Argentina. Análisis regional y departamental (2010). Tandil, IGEHCS (CONICET/UNPBA), 2016.

Recebido em 03/05/2016

Aprovado em 07/06/2017

\section{Como citar este artigo:}

MANZANO, Fernando Ariel, VELÁZQUEZ,Guillermo Angel. ¿Por qué últimos? Las peores situaciones de calidad de vida en la Argentina (2010). Contemporânea Revista de Sociologia da UFSCar, v. 7, n. 2, jul.- dez. 2017, pp. 443-464. 